\title{
STAFF-PATIENT COMMUNICATIONS IN A CHEST HOSPITAL
}

\author{
BY \\ J. W. PALMER \\ M.R.C. Epidemiological Research Unit, South Wales*
}

Of recent years the problems of human relations in hospital have attracted considerable concern, and one of the most discussed aspects of these relations is the giving of information to patients by medical and paramedical staff. The subject was discussed in detail by an international study group the proceedings of which are related by Barnes (1961), and various studies have reported that one of the most frequent complaints by hospital patients is that they are not told enough (McGhee, 1961; Cartwright, 1964). The demands of the patient are summarized by Freidson (1961) as falling chiefly and almost entirely under two heads: technical competence on the part of doctors and the taking of a personal interest in the patient. This study concentrates on matters which affect the patient's perception of personal interest being taken in him by hospital staff, and these consist mainly in the verbal and expressive exchanges which take place between him and the hospital personnel.

The aim of the interviewing programme was to interview about 200 patients aged 14 and over discharged successively from the hospital. Staff patients were excluded. Interviewing was done between January 25 and March 6, 1965.

As can be seen from Table I a successful interview was completed for 76 per cent. of patients only. Non-respondents are classified into "avoidable" and "inevitable". The "avoidable" lapses were due to two causes: either the patient left before he could be interviewed, or the discharge was not notified to the interviewer. Thus 21 per cent. of the sample were not interviewed owing to causes avoidable by administrative action. Much of this loss would not have occurred had the interviewer been resident in the hospital.

* Present address: Department of Clinical Epidemiology and Social Medicine, St. Thomas's Hospital Medical School, London, S.E.1.
TABLE I

RESPONDERS AND NON-RESPONDERS, WITH REASONS FOR NON-RESPONSE

\begin{tabular}{|c|c|c|c|c|}
\hline \multicolumn{3}{|l|}{ Patients } & Number & Per cent. \\
\hline ANALYSABLE: & .. & . & 167 & 76 \\
\hline $\begin{array}{l}\text { NOT ANALYSABLE: } \\
\text { Avoidable Causes: } \\
\text { Discharge before intervi } \\
\text { Not notified to interview }\end{array}$ & & $\begin{array}{l}\ldots \\
\cdots\end{array}$ & $\begin{array}{l}26 \\
20\end{array}$ & \\
\hline Total avoidable causes & .. & . & 46 & 21 \\
\hline $\begin{array}{l}\text { Inevitable Causes: } \\
\quad \text { Refused } \\
\text { Inadequate English } \\
\text { Schizophrenic } \quad . . \\
\text { Very deaf } . .\end{array}$ & $\begin{array}{l}\cdots \\
\because \\
\therefore\end{array}$ & $\begin{array}{l}\because \\
\because \\
\therefore\end{array}$ & $\begin{array}{l}1 \\
3 \\
1 \\
1\end{array}$ & \\
\hline Total inevitable causes & .. & .. & 6 & 3 \\
\hline SAMPLE & .. & $\ldots$ & 219 & 100 \\
\hline
\end{tabular}

Information was available from case notes on all the patients. The responders have been compared with the non-responders in respect of consultant, distance of home, sex, age, civil state, ward, length of stay, diagnosis, social class, and frequency of surgery, and as no important differences have been found, we assume in what follows that the responders are a representative sample of the whole group.

The interviews were carried out on the wards by the author. They took place whenever possible in a room or office with no third party present, but sometimes they had to be held in a recreation room where complete privacy could not be ensured.

The questions asked are set out in the Appendix. Question 10 and 18-23 inclusive were the same as those asked by Cartwright (1964) and were included to give comparability with that study. One of the aims of this study was to compare the quality of staff-patient relations in the hospital with that prevailing in other hospitals, and it was felt that Cartwright's national study was the best yardstick by which to assess conditions in a particular hospital. 
At this point a description of the indices used in this study to measure the quality of staff-to-patient communications is needed. There are five of these, and they will be referred to by the names "Diagnostic Agreement", "Satisfaction", "Articulation", "Demand", and "Hospital Image".

(1) Diagnostic agreement is derived from a comparison of the replies to Question 17 with the final diagnosis as recorded in the case notes. A similar (but not quite identical) index was used by Hugh-Jones, Tanser, and Whitby (1964), and Table II shows the frequency of agreement in the two studies. Unfortunately this comparison is unreliable, since it was not possible to fix a definite criterion by which to distinguish "agreement" from "disagreement". In the case of CANCER it was determined to accept as "agreements" only cases in which the patient used the word "growth" or "tumour". In other diagnostic categories no strict rule could be applied, nor if any rules had been devised would there have been any way of declaring with certainty that the rules for the different diagnostic groups gave results that were in any reasonable sense equivalent.

(2) Satisfaction is a measure of whether the patient feels he has been told enough about his illness, treatment, and prognosis. It is derived from Questions 18, 19, and 20. Anyone who replies No to Question 18 scores 0: others are asked Question 19 and anyone who replies YeS scores 1: those not yet scored are asked Question 20 and if they reply No they are scored 2: all those left are scored 3 . The same questions were asked in the same order by Cartwright (1964) and a direct comparison between the results for our chest hospital and those from her national survey is possible (see Table III). It appears that satisfaction in this hospital is at the average level for the country.
TABLE III

SATISFACTION, ARTICULATION, DEMAND AND IDENTIFICATION ÓF PERSONAL DÓCTOR: COMPARISON OF SUBJECTS IN THIS STUDY WITH THOSE IN CARTWRIGHT'S. (PERCENTAGES)

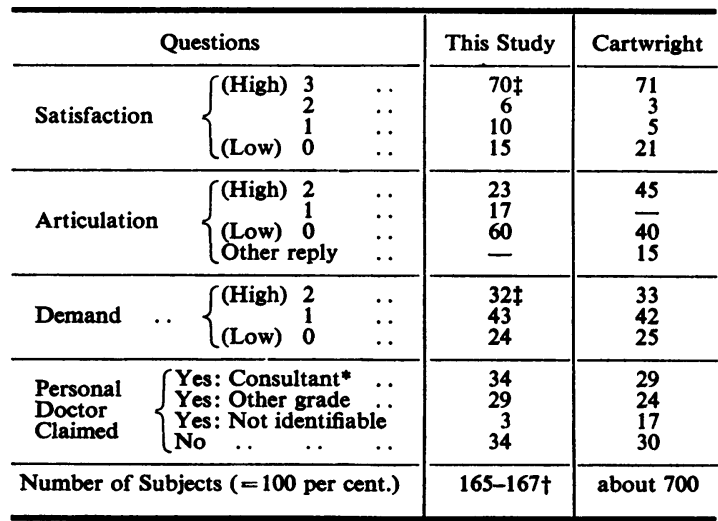

* Including S.H.M.O.'s in Cartwright's study.

+ A few subjects did not give clear replies to some questions.

$\$$ Percentages do not add to exactly 100 ; this is due to approximation.

(3) Articulation is intended to measure the extent to which patients seek information for themselves by asking questions. It is derived from Question 21 and scored from 0 to 2. Cartwright asked the same question but classified the replies according to a slightly different system; nevertheless, it can be seen from Table III that our patients ask fewer questions than hospital patients in general. This difference cannot be explained by social class differences; articulation is related to social class (see below and Table V) but the social class distributions in this study and in Cartwright's are essentially the same.

(4) Demand is intended to measure the extent to which patients want to be told the medical facts of their cases. Those who reply No to Question 22 are scored 0: the rest are asked Question 23 and scored as indicated in the interview schedule. These were

TABLE II

PATIENT'S AGREEMENT WITH DIAGNOSIS, BY DISEASE GROUPS

\begin{tabular}{|c|c|c|c|c|c|c|c|}
\hline Diagnosis & $\begin{array}{l}\text { Tuberculosis and } \\
\text { Infective }\end{array}$ & Cancer & $\begin{array}{l}\text { Heart and } \\
\text { Vascular }\end{array}$ & $\begin{array}{c}\text { Other } \\
\text { Respiratory }\end{array}$ & Other & Total & Hugh-Jones \\
\hline Agrees & 25 & 2 & 53 & 37 & 9 & 126 & 139 \\
\hline Disagrees & 5 & 20 & 7 & 8 & 1 & 41 & 35 \\
\hline Total & 30 & 22 & 60 & 45 & 10 & 167 & 174 \\
\hline \multicolumn{2}{|c|}{ Percentage Agreeing } & . & .. & . & . & 76 & 80 \\
\hline
\end{tabular}

Disease groups are defined as follows (International Classification of Diseases):

Tb. and infective: $001-09$ and $138 \quad$ Heart and vascular: 410-468, 754 .

Cancer: 160-165 Other respiratory: 421, 490-527.

Other: included all other diagnoses found in this sample, including trauma of any site or organ (N800-999). 
also questions asked by Cartwright and the distribution of replies in the present study and in her study is also set out in Table III. There appears to be no difference between the levels of demand found in the two studies; our patients appear to be about average in this respect.

(5) Hospital Image is intended to indicate whether patients perceived hospital staff as helpful or obstructive in their attitude to patients seeking information. It is derived from Question 24, the reply YES indicating that the hospital was seen to be helpful, No that it was unhelpful. There was, however, a large proportion of patients who could not answer this question. We have assumed that these patients' perceptions of the hospital were not entirely favourable, and combined them with those who answered No. The question was one devised specially for this study, so that no comparison with other studies is possible.

One other variable which is important to the following discussion is that derived from Question 10: "Do you feel there is one doctor who is your particular hospital doctor?". This question was also asked by Cartwright and, when allowance is made for the greater difficulty of tracing and identifying doctors which was inevitable in the national study, the distributions in Table III seem very similar.

The "Demand" and "Articulation" scores will be regarded as intrinsic characteristics of patients which, although they may be modified by the hospitalization experience, tend in the main to determine their response to hospitalization. The interrelation of these variables is set out in Table IV, in which the upper two levels of the articulation score have been combined. Articulation is clearly related to demand, for at the lowest level of demand, high articulation is quite uncommon. This is to be expected, since if you do not want to know much you are unlikely to ask many questions.

TABLE IV

DEMAND RELATED TO ARTICULATION

\begin{tabular}{c|c|c|c}
\hline \multirow{2}{*}{ Demand } & \multicolumn{2}{|c|}{ Articulation } & \multirow{2}{*}{ Total } \\
\cline { 2 - 3 } & High (1 \& 2) & Low (0) & \\
\hline 2 & 26 & 28 & 54 \\
1 & 34 & 38 & 72 \\
0 & 5 & 33 & 38 \\
\hline Total & 65 & 99 & $164^{*}$ \\
\hline
\end{tabular}

* A few subjects did not give clear replies to every question.

Freidson (1961) noted that middle class patients were inclined to adopt a more critical and manipulative attitude to medical care than lower class patients. A similar observation was made by Simmons and Wolff (1954). Coser (1962) distinguished patients into "outside-oriented" and "hospital-oriented" types: the latter were more passive in their acceptance of the decisions made for them by the hospital and regarded themselves for the duration of their stay as totally involved in the hospital environment, while the "outside-oriented" regarded the hospital as providing no more than a service of a defined and restricted kind and kept their main orientation in the outside world. Elsewhere, Coser (1960) remarked that the passive patient facilitated treatment, but resisted recovery: the active patient might interfere with treatment but was better equipped to recover. Shiloh (1965) distinguished "equalitarian" and "hierarchal" patients. The latter assumed a lowly position in the social structure of the hospital-roughly, it would seem, level with the cleaning women and clearly below all medical and paramedical staff-while the former regarded themselves as equal partners with the total hospital organization. Finally, Cartwright (1964) described an extreme group of "passive accepters", defining them rather stringently as patients who did not wish to be told much, asked no questions, and described no difficulty in communication, and finding that they constituted 10 per cent. of her sample. In our terms these are patients with low demand, low articulation, and very high satisfaction.

What is clear is that all these authors are referring basically to the same dimension of patient attitudes. It runs from the active participant to the passive receiver; from the demanding questioner to the undemanding accepter; and there is a strong implication that it is correlated with social class. Cartwright found the asking of questions (articulation, in our terms) to be positively related to social class and negatively to age. In our hospital both these associations were present (Table V, overleaf). We have found, however, no association between demand and social class, so that it is probably more accurate to identify the activity-passivity dimension of Coser, Shiloh, and the others with our "Articulation" rather than with "Demand". The active or equalitarian patient is distinguished not so much by his greater desire for information as by his greater inclination to ask questions. Cartwright, however, found some association between social class and demand, but only at the highest level of the demand scale; patients of higher social class were more likely to want very detailed explanations, but low demand, which indicates a desire to shut out communications on the anxiety provoking subject of one's own illness and treatment, was equally frequent in all social classes. 
TABLE V

ARTICULATION BY SOCIAL CLASS AND AGE GROUP

\begin{tabular}{|c|c|c|c|c|c|c|c|c|c|c|}
\hline \multirow{2}{*}{ Articulation } & \multicolumn{5}{|c|}{ Social Classt } & \multicolumn{4}{|c|}{ Age Group (yrs) } & \multirow{2}{*}{ Total } \\
\hline & I and II & III (Nm) & III (M) & IV & $\mathbf{V}$ & $14-29$ & $30-49$ & $50-69$ & $70-89$ & \\
\hline $\begin{array}{l}2 \\
1 \\
0\end{array}$ & $\begin{array}{r}10 \\
7 \\
14\end{array}$ & $\begin{array}{r}8 \\
3 \\
13\end{array}$ & $\begin{array}{l}17 \\
12 \\
40\end{array}$ & $\begin{array}{r}2 \\
4 \\
18\end{array}$ & $\begin{array}{r}1 \\
3 \\
14\end{array}$ & $\begin{array}{r}6 \\
8 \\
11\end{array}$ & $\begin{array}{r}13 \\
8 \\
26\end{array}$ & $\begin{array}{l}16 \\
12 \\
54\end{array}$ & $\begin{array}{l}3 \\
1 \\
8\end{array}$ & $\begin{array}{l}38 \\
29 \\
99\end{array}$ \\
\hline Total & 31 & 24 & 69 & 24 & 18 & 25 & 47 & 82 & 12 & $166^{*}$ \\
\hline Percentage 1 or 2 & 55 & 46 & 42 & 25 & 22 & 56 & 45 & 34 & 33 & \\
\hline
\end{tabular}

- One person who failed to reply excluded.

t Occupations grouped according to Registrar-General's 1960 classification. Men and single women of working age assigned to present or past occupation; retired persons to main occupation; married women and widows to husband's occupation. $\mathbf{N m}=\mathbf{n o n}-\mathbf{m a n u a l}$ : $\mathbf{M}=\mathbf{M a n u a l}$.

Table VI relates satisfaction with communications and "Hospital Image" (that is, the patient's perception of whether the hospital atmosphere encourages the obtaining of information by patients) to Articulation and Demand. Articulation by itself does not seem strongly to influence either satisfaction or hospital image, but it is notable that the most dissatisfied group and the group with the least favourable perception of the hospital atmosphere is the "low articulation-high demand" group. In short, the most dissatisfied patients are those who want to be told a lot but do not ask questions. These are probably the group who are inhibited by perceiving a marked difference of social status between themselves and the doctor.

It is sometimes stated that it is the middle-class, educated, or intelligent patient who expects the most detailed explanations from his doctor, while the lower-class patient is more likely to be a passive accepter. This statement requires considerable qualification. We have found that the asking of questions is positively associated with social class; thus the middle-class patient will appear to want more information simply because he is more articulate, while the desire for information of the lower class patient will tend to be concealed. Besides this, it is clear that not wanting information, in the sense of preferring not to be told, is not at all infrequent and is equally common in all social classes. Finally, a desire for much information coupled with a dislike for asking questions seems to produce the most dissatisfaction. The greater apparent demand for information by middle-class patients, then, is due to two things: a real difference, in that they are more likely to want explanations of a technical kind; and a mere appearance due to their greater articulateness.

It also seems that a large number of patients are not getting the information they want because of reluctance to ask questions. It follows that what the doctor needs to know, in explaining his case to the patient, is first of all how much the patient wants to know: the patient's social class, intelligence, or education may dictate the language in which the explanation should be given, but should not dictate its completeness.

TABLE VI

SATISFACTION AND HOSPITAL IMAGE RELATED TO DEMAND AND ARTICULATION

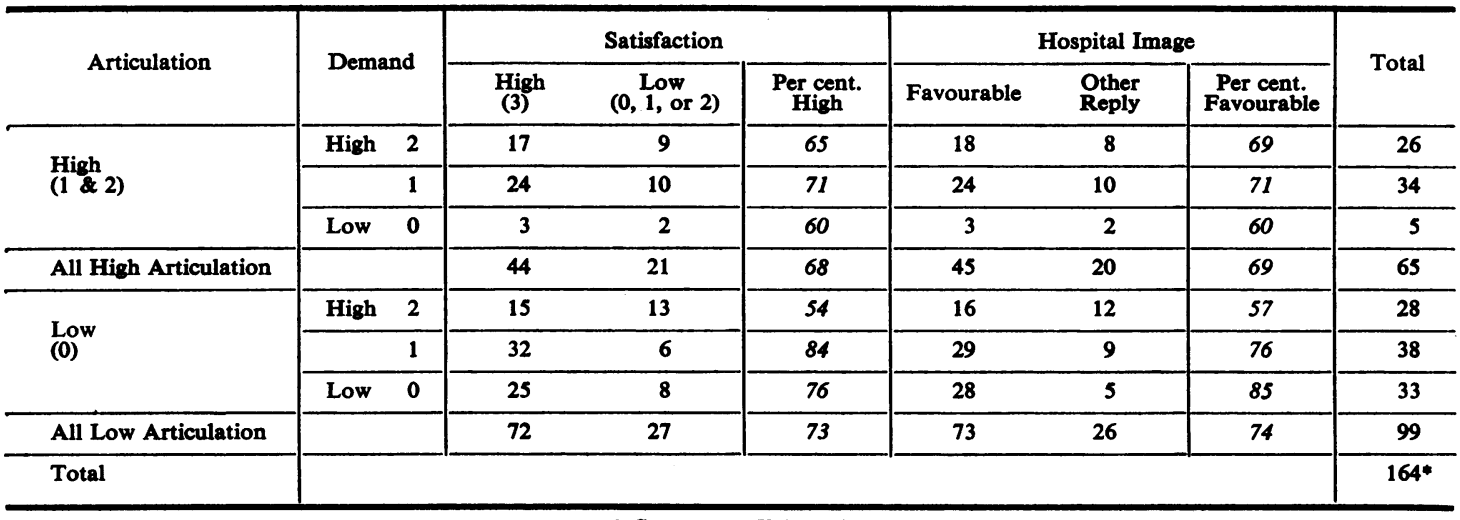

- See note to Table IV. 


\section{Communications and having a "Personal DOCTOR"}

The Joint Sub-committee of the Standing Medical and Standing Nursing Advisory Committees for the Central Health Services Council and the Minister of Health, under the chairmanship of Lord Cohen of Birkenhead, has recently reported on communication between doctors, nurses, and patients (Ministry of Health, 1963). They recommend that every patient in hospital should have a personal doctor whose duty it should be to impart information to the patient; that this doctor should be officially appointed and his identity clearly known to the patient and to all staff; and that he should be available for inquiries by the patient and his relatives. This personal doctor should be the consultant in charge of the case or any other doctor to whom the consultant delegates this responsibility. In this way it is hoped that failures in doctor-patient communication will be minimized. Cartwright (1964, p. 113-4) puts forward a similar proposal.

Our hypothesis is that patients who consider that they have a personal doctor in hospital will receive better information and be more satisfied with communications than those who do not. The consequent predictions are that patients who consider they have a "personal doctor" in hospital will show a higher degree of satisfaction with communications, will have received better information (as indicated by the frequency with which they agree with the case-notes diagnosis), and will have a more favourable "hospital image". None of these predictions is clearly confirmed in Table VII, but it does appear that those who considered they had a "personal doctor" asked more questions and tended to be of a higher social class (Table VIII) than those who did not distinguish a "personal doctor". It may be that having a "personal doctor" facilitates the asking of questions; or that if a patient wants to ask questions he is inclined to pick a single member of the staff to whom to address them. ${ }^{*}$ A third possibility is that members of the higher social classes expect to have a personal doctor in hospital and are more likely to distinguish doctors by name, while members of lower social classes are inclined to think of all doctors as just "doctors"; but explanations involving social class should be cautiously entertained in view of the fact that Cartwright (1964, p. 194) did not find any association between recognizing a personal doctor and social class.

It may be, then, that if people who at present are inhibited from asking doctors questions could be encouraged to do so, some of the most dissatisfied persons-namely the "inarticulate" but "demanding" group (see Table VI) could be better satisfied. However, patients who merely claim personal doctors are not better satisfied: the hypothesis, as we have defined it, is not supported. What is needed is a definite organizational change by which staff will undertake the imparting of information to patients as a major function. The effect of such a change has yet to be tested, and until it is it would be wrong to dismiss the recommendations of the Cohen Committee (1963).

* Some support for this is furnished by Cartwright (1964), p. 94, Table 16.

TABLE VII

PATIENTS' RECOGNITION OF A “PERSONAL DOCTOR” IN RELATION TO COMMUNICATION VARIABLES

\begin{tabular}{|c|c|c|c|c|c|c|c|}
\hline \multirow{2}{*}{ Recognition } & \multirow{2}{*}{$\begin{array}{l}\text { Diagnostic } \\
\text { Agreement } \\
\text { (Per cent. } \\
\text { agreeing) }\end{array}$} & \multirow{2}{*}{$\begin{array}{l}\text { Satisfaction } \\
\text { (Per cent. } \\
\text { "high" } \\
\text { (score 3)) }\end{array}$} & \multirow{2}{*}{$\begin{array}{l}\text { Articulation } \\
\text { (Per cent. } \\
\text { "high" } \\
\text { (score 1 or 2)) }\end{array}$} & \multicolumn{2}{|c|}{ Demand } & \multirow{2}{*}{$\begin{array}{c}\text { Hospital } \\
\text { Image } \\
\text { (Per cent. } \\
\text { "favourable") }\end{array}$} & \multirow{2}{*}{$\begin{array}{c}\quad n \\
(=100 \\
\text { per cent. })\end{array}$} \\
\hline & & & & $\begin{array}{c}\text { (Per cent. "low" } \\
\text { (score 0)) }\end{array}$ & $\begin{array}{l}\text { (Per cent. "high" } \\
\text { (score 2)) }\end{array}$ & & \\
\hline $\begin{array}{l}\text { Patients who named or } \\
\text { recognized a "personal } \\
\text { doctor" }\end{array}$ & 74 & $72 *$ & $47 t$ & 20 & 32 & 71 & 110 \\
\hline 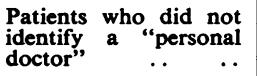 & 79 & 67 & 28 & 32 & 33 & 72 & 57 \\
\hline
\end{tabular}

" Two did not reply to "satisfaction" questions and were excluded from denominator in calculating percentages. † One did not reply to "articulation" question and was excluded from denominator in calculating percentages.

TABLE VIII

PERCENTAGes Claiming A PERSONAL DOCTOR, By SOCIAL Class

\begin{tabular}{|c|c|c|c|c|c|c|c|}
\hline Social Class & & I and II & III (Nm) & III (M) & IV & $\mathbf{V}$ & All Social Classes \\
\hline $\begin{array}{l}\text { Per cent. claiming personal doctor } \\
n(=100 \text { per cent.) }\end{array}$ & . & $\begin{array}{l}81 \\
32\end{array}$ & $\begin{array}{l}63 \\
24\end{array}$ & $\begin{array}{l}62 \\
69\end{array}$ & $\begin{array}{l}67 \\
24\end{array}$ & $\begin{array}{l}56 \\
18\end{array}$ & $\begin{array}{r}66 \\
167\end{array}$ \\
\hline
\end{tabular}


Communications in Relation to Diagnosis

It seems likely that the quality of the information received by the patient, and his satisfaction with it, varies with the nature of his disease. This is crudely obvious with cancer, in which much information is deliberately withheld from the patient, but we have attempted to make the hypothesis more generally applicable. In the form examined here, it is: "the information received by the patient is most complete and gives most satisfaction when $(a)$ the course of treatment for the disease is most predictable, $(b)$ the treatment is specific and effective, $(c)$ the prognosis is most favourable". These three dimensions (a), (b), and (c) are obviously correlated together. It appears that diseases can frequently be classified according to these three dimensions together and placed in a definite rank order. Three examples are given below:

$\begin{array}{ccr}\text { Disease } & \begin{array}{c}\text { Course of } \\ \text { Treatment }\end{array} & \text { Prognosis } \\ \text { Pulmonary Tuberculosis } & \begin{array}{c}\text { Generally highly } \\ \text { predictable and } \\ \text { highly specific }\end{array} & \text { Good } \\ \text { Rheumatic Heart Disease } & \begin{array}{c}\text { Predictable and } \\ \text { moderately } \\ \text { effective } \\ \text { Not predictable } \\ \text { and not specific }\end{array} & \text { Uncertain } \\ \text { Cancer of Lung } & \text { Bad }\end{array}$

It follows, therefore, that communications will be best in pulmonary tuberculosis, intermediate in rheumatic heart disease, and worst in lung cancer.

Table IX shows the statistics relating to this supposition, and the hypothesis is far from being supported. Cancer patients are, of course, generally unaware of the diagnosis, but there is no difference between the other two groups on this variable. Patients with cancer, express, paradoxically, the highest satisfaction, whereas those with tuberculosis show the highest articulation and demand and the most unfavourable perception of the hospital image.

The explanation may be that tuberculous patients, having remained in the hospital a long time, have become unfavourably impressed with the institution as a whole and impatient to leave, and in consequence are not only anxious to know one main thing when they will be able to leave-but are inclined to ask questions about this also. This does not, however, seem to be an invariable effect of long stay, since when all patients were taken together length of stay was not found to have any well-defined effect on articulation, demand, or hospital image. There may well be something about the social situation of the tuberculous patient, perhaps connected with the combination of being ambulant and not greatly disabled as well as remaining in hospital a long time, which makes him particularly anxious for information. Roth (1963) makes some observations relevant to this.

\section{SUMMARY}

This paper reports an interview study of patients in a chest hospital, which aimed to elicit their opinions of the quality of staff-to-patient communications. The results are in general agreement with the national study of Cartwright (1964).

There seems to exist a group of dissatisfied patients, of lower social class, who desire fuller information but are reluctant to ask for it.

It is considered that the recommendations of the Cohen Committee of the Ministry of Health (1963) on communications in hospital require experimental implementation in order to test their effectiveness.

The quality of communications varied with the diagnosis, but not in the direction predicted. Tuberculous patients in particular seem to experience a frustrated desire for information.

The author wishes to acknowledge his debt to $\mathrm{Dr}$ H. M. Foreman, who, as Physician Superintendent of the hospital, initiated the study and gave much encouragement; to Mr D. Llewellyn, Medical Records Officer, without whose constant co-operation (and forbearance!) the study could not have been carried out; to the nursing staff who freely gave access to the wards to interview patients; to many of the hospital staff who made helpful suggestions and especially to Dr G. S. Kilpatrick for his constant interest; and to Professor A. L. Cochrane for allowing this study to be carried out as a project of the Epidemiological Research Unit.

TABLE IX

DIAGNOSIS IN RELATION TO COMMUNICATION VARIABLES

\begin{tabular}{|c|c|c|c|c|c|c|c|c|c|}
\hline \multirow[b]{2}{*}{ Diagnosis } & & & \multirow{2}{*}{$\begin{array}{l}\text { Diagnostic } \\
\text { Agreement } \\
\text { (Per cent. } \\
\text { agreeing) }\end{array}$} & \multirow{2}{*}{$\begin{array}{l}\text { Satisfaction } \\
\text { (Per cent. } \\
\text { "high" } \\
\text { (score 0)) }\end{array}$} & \multirow{2}{*}{$\begin{array}{l}\text { Articulation } \\
\text { (Per cent. } \\
\text { "high" } \\
\text { (score } 1 \text { or 2)) }\end{array}$} & \multicolumn{2}{|c|}{ Demand } & \multirow{2}{*}{$\begin{array}{c}\text { Hospital } \\
\text { Image } \\
\text { (Per cent. } \\
\text { "favourable") }\end{array}$} & \multirow{2}{*}{$\begin{array}{c}n \\
(=100 \\
\text { per cent. })\end{array}$} \\
\hline & & & & & & $\begin{array}{l}\text { (Per cent. } \\
\text { "low" } \\
\text { (score 0)) }\end{array}$ & $\begin{array}{l}\text { (Per cent. } \\
\text { "high" } \\
\text { (score 2)) }\end{array}$ & & \\
\hline $\begin{array}{l}\text { Respiratory Tuberculosis } \\
\text { (I.C.D. 001-007) } \\
\text { Respiratory Cancer } \\
\text { (I.C.D. 160-165) } \\
\text { Rheumatic Heart Disease } \\
\text { (I.C.D. 410-416) } \quad \text {. }\end{array}$ & $\begin{array}{l}\cdots \\
\cdots \\
\cdots\end{array}$ & $\begin{array}{l}\cdots \\
\cdots \\
\cdots\end{array}$ & $\begin{array}{r}84 \\
9 \\
89\end{array}$ & $\begin{array}{l}72 \\
86 * \\
67\end{array}$ & $\begin{array}{l}56 \\
45\end{array}$ & $\begin{array}{l}24 \\
23\end{array}$ & $\begin{array}{r}32 \\
9 \\
19\end{array}$ & $\begin{array}{l}60 \\
73\end{array}$ & $\begin{array}{l}25 \\
22\end{array}$ \\
\hline
\end{tabular}

- One did not reply to "satisfaction" questions and was excluded from denominator in calculating percentages. 


\section{REFERENCES}

Barnes, E. (1961). "People in Hospital". Macmillan, London.

Cartwright, A. (1964). "Human Relations and Hospital Care". Routledge and Kegan Paul, London.

Coser, R. L. (1960). "A Home away from Home", in "Sociological Studies of Health and Sickness", ed. D. Apple, p. 168. McGraw-Hill, New York.

(1962). "Life in the Ward". Michigan State University Press.

Freidson, E. (1961). "Patients' Views of Medical Practice". Russell Sage Foundation, New York.

Hugh-Jones, P., Tanser, A. R., and Whitby, C. (1964). Brit. med. J., 2, 660.
McGhee, A. (1961). "The Patient's Attitude to Nursing Care". Livingstone, Edinburgh.

Ministry of Health (1963). "Communication between Doctors, Nurses and Patients". Report of a Joint Subcommittee of the Standing Medical and Standing Nursing Advisory Committees for the Central Health Services Council and the Minister of Health (Chairman: Lord Cohen of Birkenhead). H.M.S.O., London.

Roth, J. A. (1963). "Timetables: Structuring the Passage of Time in Hospital Treatment and Other Careers". Bobbs-Merrill, New York.

Shiloh, A. (1965). Med. Care, 3, 87.

Simmons, L. W., and Wolff, H. G. (1954). "Social Science in Medicine". Russell Sage Foundation, New York.

\section{APPENDIX}

\section{THE INTERVIEW SCHEDULE}

Only those questions which are alluded to in the preceding discussion are given here, although other questions were also asked in the interviews. The alternative answers stated were not spoken or suggested by the interviewer, but used only for categorizing the replies.

Q.10 Do you feel there is one doctor who is your particular hospital doctor? .. No

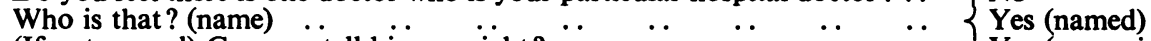

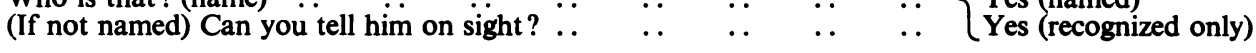

Q.17 What have you been in hospital for-what illness?

(record)

Q.18

Have you been able to find out all you want to know about your condition,

$\left\{\begin{array}{l}\text { No } \\ \text { Yes }\end{array}\right.$

SATISFACTION SCORE

treatment, and progress?

0

go on

Q.19 Is there anything in particular that you would like to have explained in $\{$ Yes 1

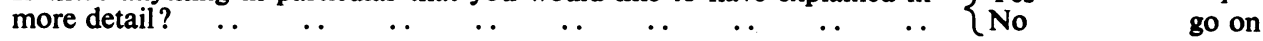

What is that? (record)

Q.20

Have you been able to find out things as soon as you would like? ..

$\ldots \quad\left\{\begin{array}{l}\text { No } \\ \text { Yes }\end{array}\right.$

2

What haven't you been able to find out? (record)

Q.21 Did you ask questions about things or did the doctors and nurses tell you of their own accord? Which was it mainly?

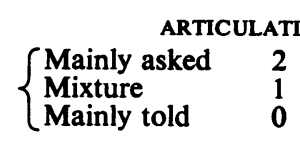

ARTICULATION SCORE 